\title{
Novel molecular changes induced by Nrg1 hypomorphism and Nrg1-cannabinoid interaction in adolescence: a hippocampal proteomic study in mice
}

\author{
Jarrah R. Spencer 1,2, Keturah M. E. Darbyshire ${ }^{1}$, Aurelie A. Boucher ${ }^{2}$, Mohammed A. Kashem $^{3}$, \\ Leonora E. Long ${ }^{4,5,6}$, lain S. McGregor ${ }^{3}$, Tim Karl ${ }^{4,5,6}$ and Jonathon C. Arnold ${ }^{1,2,5 *}$ \\ ' Discipline of Pharmacology, University of Sydney, Sydney, NSW, Australia \\ ${ }^{2}$ Brain and Mind Research Institute, University of Sydney, Sydney, NSW, Australia \\ ${ }^{3}$ School of Psychology, University of Sydney, Sydney, NSW, Australia \\ ${ }^{4}$ Neuroscience Research Australia, Randwick, NSW, Australia \\ ${ }^{5}$ Schizophrenia Research Institute, Darlinghurst, NSW, Australia \\ ${ }^{6}$ School of Medical Sciences, University of New South Wales, Kensington, NSW, Australia
}

Edited by:

Chao Deng, University of

Wollongong, Australia

Reviewed by:

Georg Kohr, Max Planck Institute

for Medical Research, Germany

Mikhail Pletnikov, Johns Hopkins

University, USA

${ }^{*}$ Correspondence:

Jonathon C. Arnold, Discipline of

Pharmacology, University of Sydney,

Building D05, Camperdown,

NSW 2006, Australia.

e-mail: jonathon.arnold@

sydney.edu.au
Neuregulin 1 (NRG1) is linked to an increased risk of developing schizophrenia and cannabis dependence. Mice that are hypomorphic for Nrg1 (Nrg1 HET mice) display schizophrenia-relevant behavioral phenotypes and aberrant expression of serotonin and glutamate receptors. Nrg1 HET mice also display idiosyncratic responses to the main psychoactive constituent of cannabis, $\Delta^{9}$-tetrahydrocannabinol (THC). To gain traction on the molecular pathways disrupted by $\mathrm{Nrg} 1$ hypomorphism and $\mathrm{Nrg} 1$-cannabinoid interactions we conducted a proteomic study. Adolescent wildtype (WT) and Nrg1 HET mice were exposed to repeated injections of vehicle or THC and their hippocampi were submitted to 2D gel proteomics. Comparison of WT and Nrg1 HET mice identified proteins linked to molecular changes in schizophrenia that have not been previously associated with Nrg1. These proteins are involved in vesicular release of neurotransmitters such as SNARE proteins; enzymes impacting serotonergic neurotransmission, and proteins affecting growth factor expression. Nrg1 HET mice treated with THC expressed a distinct protein expression signature compared to WT mice. Replicating prior findings, THC caused proteomic changes in WT mice suggestive of greater oxidative stress and neurodegeneration. We have previously observed that THC selectively increased hippocampal NMDA receptor binding of adolescent Nrg1 HET mice. Here we observed outcomes consistent with heightened NMDA-mediated glutamatergic neurotransmission. This included differential expression of proteins involved in NMDA receptor trafficking to the synaptic membrane; lipid raft stabilization of synaptic NMDA receptors; and homeostatic responses to dampen excitotoxicity. These findings uncover novel proteins altered in response to $\mathrm{Nrg} 1$ hypomorphism and $\mathrm{Nrg} 1$-cannabinoid interactions that improves our molecular understanding of $\mathrm{Nrg} 1$ signaling and $\mathrm{Nrg} 1$-mediated genetic vulnerability to the neurobehavioral effects of cannabinoids.

Keywords: Nrg1, THC, mouse, hippocampus, schizophrenia, proteomics

\section{INTRODUCTION}

Neuregulin $1(\mathrm{Nrg1})$ is a neurotrophic factor that mediates its effects by binding ErbB receptor tyrosine kinases. Nrg1 regulates axonal guidance, myelination, and GABAergic and glutamatergic neurotransmission (Mei and Xiong, 2008). The human NRG1 gene has been linked to schizophrenia by genetic studies (Stefansson et al., 2002; Ayalew et al., 2012) and altered expression of NRG1 isoforms has been measured in schizophrenia patients (Hashimoto et al., 2004; Chong et al., 2008; Marballi et al., 2012; Weickert et al., 2012). NRG1 variants have been associated with dysfunction in a number of schizophrenia-relevant "endophenotypes" including sensorimotor gating as measured by prepulse inhibition of startle (PPI) (Hong et al., 2008; Roussos et al., 2011; Greenwood et al., 2012) and working memory (Chong et al., 2008).

Use of transgenic murine models can be useful in exploring the role of $\mathrm{Nrgl}$ in molecular neurobiology and behavior. The most extensively studied mouse model of $\mathrm{Nrg} 1$ dysfunction is the $\mathrm{Nrg1}$ transmembrane heterozygous ( $\mathrm{Nrg} 1 \mathrm{HET}$ ) mouse which exhibits locomotor hyperactivity and protocol-dependent PPI deficits (Stefansson et al., 2002; Karl et al., 2007; Spencer et al., 2012). These mice display altered anxiety profiles, inhibited preference for social novelty and increased levels of aggressive social interaction as well as impaired performance in novel object 
recognition and fear conditioning paradigms (Karl et al., 2007; O’Tuathaigh et al., 2007, 2008; Duffy et al., 2010; Desbonnet et al., 2012). Hypo-phosphorylation of the NR2B subunit of the NMDA receptor is observed in Nrg1 HET mice (Bjarnadottir et al., 2007). Together, these findings provide some clues of the molecular and neurobiological alterations that mediate the aberrant behavioral phenotypes exhibited by Nrg1 HET mice.

Adolescence is particularly relevant to schizophrenia given the onset of the disorder typically occurs in late adolescence. During adolescence there exists significant synaptic pruning and a shift between utilization of mesolimbic and mesocortical areas of the brain which indicates a high level of neural development during this period (Giedd et al., 1999; Spear, 2000; Casey et al., 2008). Nrg1 HET mice display developmentally-specific neurobiological and behavioral phenotypes, for example, adolescent $\mathrm{Nrg} 1$ HET mice have reduced 5- $\mathrm{HT}_{2 \mathrm{~A}}$ receptor expression in the insular and cingulate cortices (Long et al., 2013) in contrast to the global increase in $5 \mathrm{HT}_{2 \mathrm{~A}}$ receptor expression observed in adult Nrg1 HET mice relative to controls (Dean et al., 2008). Nrg1 HET mice display an enhanced stress-induced release of corticosterone relative to wildtype (WT) controls at 3-4 months of age, an effect that disappears by 5-6 months (Chesworth et al., 2012). Together these findings point toward the Nrgl HET mouse being a particularly suitable model for demonstrating a role for $\mathrm{Nrgl}$ in developmental stage-specific neurobehavioral alterations.

Drug dependence and schizophrenia are comorbid disorders that may have common genetic and neurobiological substrates. Genetic vulnerability is thought to explain why only a subset of cannabis users become dependent on cannabis or develop psychosis. A recent study demonstrated that NRG1 increased the risk of cannabis dependence in African-Americans (Han et al., 2012). We have shown Nrg1 HET mice display distinct schizophrenia-relevant neurobehavioral responses to cannabinoids, including the main psychoactive constituent of cannabis, $\Delta^{9}$-tetrahydrocannabinol (THC). Acute cannabinoid exposure promoted PPI facilitation in Nrg1 HET mice but PPI deficits in WT mice (Boucher et al., 2007a, 2011). Nrg1 genotype also modulated tolerance to the effects of cannabinoids, with Nrg1 HET mice developing tolerance more rapidly to locomotor suppression and hypothermia than WT mice, but conversely showing a lack of tolerance to cannabinoid-induced anxiety unlike WT mice (Boucher et al., 2011). The acute and repeated effects of cannabinoids correlate with selective changes in Fos transcription factor expression in the lateral septum of Nrg1 HET mice that were not observed in WT mice (Boucher et al., 2007b, 2011). In adolescence $\mathrm{Nrg} 1$ modulated the effects of repeated THC exposure on the expression of neurotransmitter receptors relevant to the pathophysiology of schizophrenia (i.e., $\mathrm{CB}_{1}, \mathrm{NMDA}$, and 5- $\mathrm{HT}_{2 \mathrm{~A}}$ receptors) (Long et al., 2013).

The hippocampus may be an important region for Nrg1cannabinoid interactions as both endocannabinoid and Nrg1ErbB systems are highly expressed in this brain region (Herkenham et al., 1990; Tsou et al., 1998; Vullhorst et al., 2009). We have observed increased brain transcriptional activity in the lateral septum at baseline and following cannabinoid exposure in Nrg1 HET mice, both of which might reflect downstream effects of aberrant activity in the hippocampus as part of the septohippocampal system. Therefore, molecular changes in the hippocampus may subserve the distinct neurobehavioral phenotypes displayed by $\mathrm{Nrg} 1 \mathrm{HET}$ mice as well as their altered response to THC. Of particular interest is our observation that adolescent THC-treated Nrg1 HET mice display increased NMDA receptor expression in the hippocampus, something not observed in THC-treated WT mice (Long et al., 2013). Here we aim to gain some traction on the molecular mechanisms involved in the aberrant phenotypes exhibited by Nrg1 HET mice at baseline and when exposed to THC using a proteomic approach which allows us to detect changes in hundreds of different proteins in the hippocampus.

\section{MATERIALS AND METHODS ANIMALS AND DRUG TREATMENT}

At the commencement of the study adolescent male Nrg1 HET mice and WT littermates (C57/BL6 background strain) were at an age of post-natal day (PND) $31 \pm 2$. The study was restricted to male mice as male $\mathrm{Nrgl}$ HET mice appear more vulnerable to the effects of cannabinoids (Long et al., 2010). Mice were pair-housed at Neuroscience Research Australia with limited environmental enrichment [certified polycarbonate mouse igloo (Bioserv, USA) and a metal ring in the cage lid] under a $12 \mathrm{~h}$ light/dark schedule (lights on $08: 30 \mathrm{~h}$ ) and genotyped as previously detailed (Karl et al., 2007). Food and water were available ad libitum. THC (THC Pharm GmbH, Germany) was suspended in a 1:1:18 mixture of ethanol:Tween 80:0.9\% saline and injected intraperitoneally at a volume of $10 \mathrm{ml} / \mathrm{kg}$. Mice were injected daily with either $10 \mathrm{mg} / \mathrm{kg}$ of THC or vehicle for 21 days. During this time mice were repeatedly behaviorally tested, the results of which are published elsewhere (Long et al., 2013). Two days following the completion of treatment, the mice $(n=8)$ were euthanized by cervical dislocation, with both hippocampi dissected out and snap frozen on dry ice for proteomic analysis. Research and animal care procedures were approved by the University of New South Wales Animal Care and Ethics Committee and were in accordance with the Australian Code of Practice for the Care and Use of Animals for Scientific Purposes.

\section{PROTEIN EXTRACTION}

Protein extraction was performed using a protocol optimized for cytosolic proteins (Quinn et al., 2008). Hippocampal tissue was homogenized in buffer consisting of $7 \mathrm{M}$ urea, $2 \mathrm{M}$ thiourea, $1 \%$ C7bZO and $40 \mathrm{mM}$ Tris, sonicated and pelleted. The supernatant was reduced and alkylated in $5 \mathrm{mM}$ tributylphosphine (TBP) and $10 \mathrm{mM}$ acrylamide monomer and quenched using $10 \mathrm{mM}$ dithiothreitol (DTT). The mixture was acidified to $\mathrm{pH} 6.0$ using concentrated citric acid and precipitated with acetone. The precipitate was pelleted, air-dried and resuspended in $7 \mathrm{M}$ urea, $2 \mathrm{M}$ thiourea and $1 \%$ C7bZO.

\section{D GEL ELECTROPHORESIS}

Sample protein concentration was determined using the Bradford Protein Assay (Thermoscientific, USA). Immobilized $\mathrm{pH}$ gradient strips (IPG strips; $11 \mathrm{~cm}, \mathrm{pH} \mathrm{4-7)}$ ) were rehydrated with samples containing $600 \mu \mathrm{g}$ protein, and samples were separated by isoelectric point (pI). Strips were equilibrated in 
SDS equilibration buffer and loaded onto SDS-PAGE gradient gels $(8-16 \%, 10 \times 15 \mathrm{~cm})$ and separated by molecular weight using an ElectrophoretIQ3 system $\left(30 \mathrm{~mA} /\right.$ gel, $25^{\circ} \mathrm{C}$ for $110 \mathrm{~min}$; Proteome Systems, Australia). Gels were fixed with methanol $[25 \%(\mathrm{v} / \mathrm{v})]$ and acetic acid $[10 \%(\mathrm{v} / \mathrm{v})]$ and visualized using Flamingo Fluorescent gel stain (BioRad, USA).

\section{IMAGE ANALYSIS}

Gels were analyzed using Phoretix 2D Expression software (Nonlinear Dynamics Ltd, UK). Averaged gels were created for each experimental group and averaging parameters were set at $70 \%$. Single factor ANOVAs $(p<0.05)$ of spot volume were performed to determine the effect of genotype in vehicle-treated animals, the effect of THC administration in WT mice and the effect of THC administration in Nrg1 HET mice.

\section{MASS SPECTROMETRY AND PROTEIN IDENTIFICATION}

Protein spots that were identified as significantly altered were digested in $12.5 \mathrm{ng} / \mathrm{mL}$ trypsin (Roche, USA) and $25 \mathrm{nM}$ $\mathrm{NH}_{4} \mathrm{HCO}_{3} / 0.1 \%$ trifluroacetic acid and purified using $\mathrm{C}_{18}$ purification tips (Eppendorf, Germany) before being eluted in $3 \mu \mathrm{L}$ of matrix solution. Spots were analyzed using an Applied Biosystems QSTAR MALDI-TOF mass spectrometer (Australian Proteome Analysis Facility, University of Sydney). MALDI spectra were matched against the Swiss-Prot database using the MASCOT search engine with matches determined by molecular weight search score (MWS) and sequence coverage in conjunction with $\mathrm{pI}$ and molecular weight as estimated from gels.

\section{IMMUNOBLOTTING}

Ten ug of protein per lane was separated by electrophoresis using $10 \%$ precast NuPage gels (Invitrogen, USA) and run at $110 \mathrm{~V}$ for $2 \mathrm{~h}$. The samples were transferred to PVDF membranes. Membranes were sequentially incubated with Syntaxin-1A antibody (Sigma Aldrich, USA 1:1500) then swine anti-rabbit secondary antibody (DAKO, Australia, 1:200) and rabbit Peroxidase-Anti-Peroxidase (Sigma-Aldrich, USA 1:200) and DAB (DAKO, Australia). Membranes were stripped using Re-blot plus strong antibody stripping solution (Millipore, Australia) and incubated sequentially with Abcam rat monoclonal YL1/2 $\alpha$-tubulin (TUBA) antibody (Sapphire Biosciences Pty Ltd, Australia, 1:) then anti-rat IgG (HpL) horseradish peroxidase conjugate (Santa Cruz Biotechnology Inc, USA) and visualized using a Syngene G:Box.

\section{RESULTS}

Here we present the results of a hippocampal proteomic study conducted on adolescent Nrg1 HET mice and WT control mice treated with or without THC. The averaged gels for WT vehicle, WT THC, Nrg1 HET vehicle and Nrg1 HET THC contained $870,821,761$, and 742 spots respectively. 26 spots were significantly different between WT vehicle and Nrg1 HET vehicle mice. Of these spots, 17 proteins were identified using MALDITOF MS and the fold changes from control WT mice are listed in Table 1. Figure 1A shows a representative 2D gel image of protein expression in the hippocampus of a WT mouse administered vehicle. Normalized spot volumes are depicted for three representative proteins are shown in Figure 1B, i.e., syntaxin 1A (STX1A), beta-soluble N-ethylmaleimide-sensitive factor attachment protein ( $\beta$-SNAP) and glypican 6 (GPC6). Western blotting results confirmed Nrg1 HET mice displayed increased expression of STX1A compared to WT mice (see Figure 1B).

THC induced changes in 28 spots and 23 spots in WT and Nrg1 HET mice respectively relative to vehicle-treated mice within the same genotype. From these comparisons, 4 and 10 proteins were identified as being significantly altered by THC exposure in adolescent WT and Nrg1 HET mice and fold changes are listed in Table 2 (relative to WT mice treated with vehicle) and 3 (relative to Nrg1 HET mice treated with vehicle) respectively. Figure $2 \mathrm{~A}$ shows a representative $2 \mathrm{D}$ gel image of protein expression in the hippocampus of an adolescent WT mouse administered repeated THC injections. Normalized spot volumes are depicted for 3 representative proteins in Figure 2B, i.e., glutathione S-transferase Mu 2 (GSTM2), calretinin (CALB2) and ADP-ribosylation factor-like protein 1 (ARL1). Nrg1 HET mice treated with THC displayed a distinct protein expression profile to WT mice exposed to the drug. Figure 3A shows a representative $2 \mathrm{D}$ gel image of protein expression in the hippocampus of an adolescent $\mathrm{Nrgl}$ HET mouse administered repeated THC. Normalized spot volumes of three representative proteins are depicted in Figure 3B, i.e., G-protein-signaling modulator 2 (GPSM2), apolipoprotein A1 (APOA1) and N-acyl-phosphatidylethanolamine-hydrolyzing phospholipase D (NAPEPLD).

\section{DISCUSSION}

Nrg1 HET mice, displayed altered expression of a number of proteins involved in the vesicular release of neurotransmitters including STX1A, syntaxin 7 (STX7) and $\beta$-SNAP; serotonergic neurotransmission including tryptophan 5-hydroxylase 1 (TPH1) and serotonin N-acetyltransferase (AA-NAT); growth factor expression and regulation including secreted protein acidic and rich in cysteine (SPARC) and GPC6, and; cell survival and regulators of inflammatory cytokines including cell death regulator Aven (AVEN), TNFAIP3-interacting protein 2 (ABIN2) and regulator of G-protein signaling 10 (RGS10). We replicated prior findings in rodents without genetic modification showing THC reduced the hippocampal expression of GSTM2 and affected the expression of heat shock proteins (here HSPA4). We also identified novel proteins changed in response to repeated THC exposure, that is, CALB2 and ARL1. Unlike WT mice, Nrg1 HET mice administered THC displayed altered expression of proteins involved in NMDA receptor trafficking to the synaptic membrane including GPSM2; lipid raft stabilization of receptors at the synaptic membrane including flotillin-1 (FLOT1); homeostatic responses to dampen excessive glutamatergic transmission, including NAPEPLD, and excitotoxicity and apoptosis including programmed cell death protein 2 (PCD2). Figure 4 is a schematic proposing an overview of the proteins found to have altered expression in the current study and their potential functional significance. Proteomics may produce false positives and fold changes $<1.5$ should be interpreted cautiously. Nevertheless, these results, while suggestive rather than conclusive, provide 


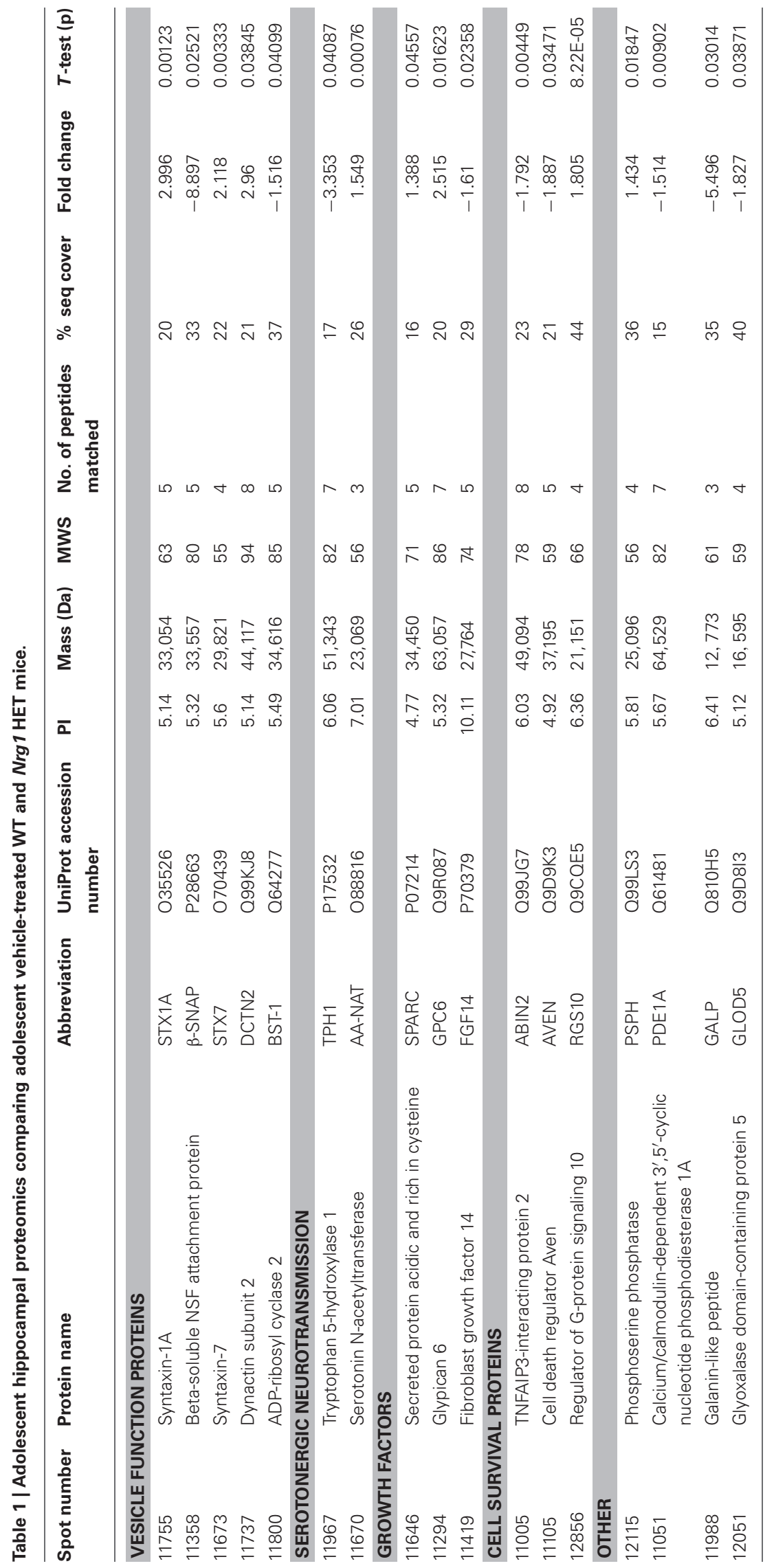




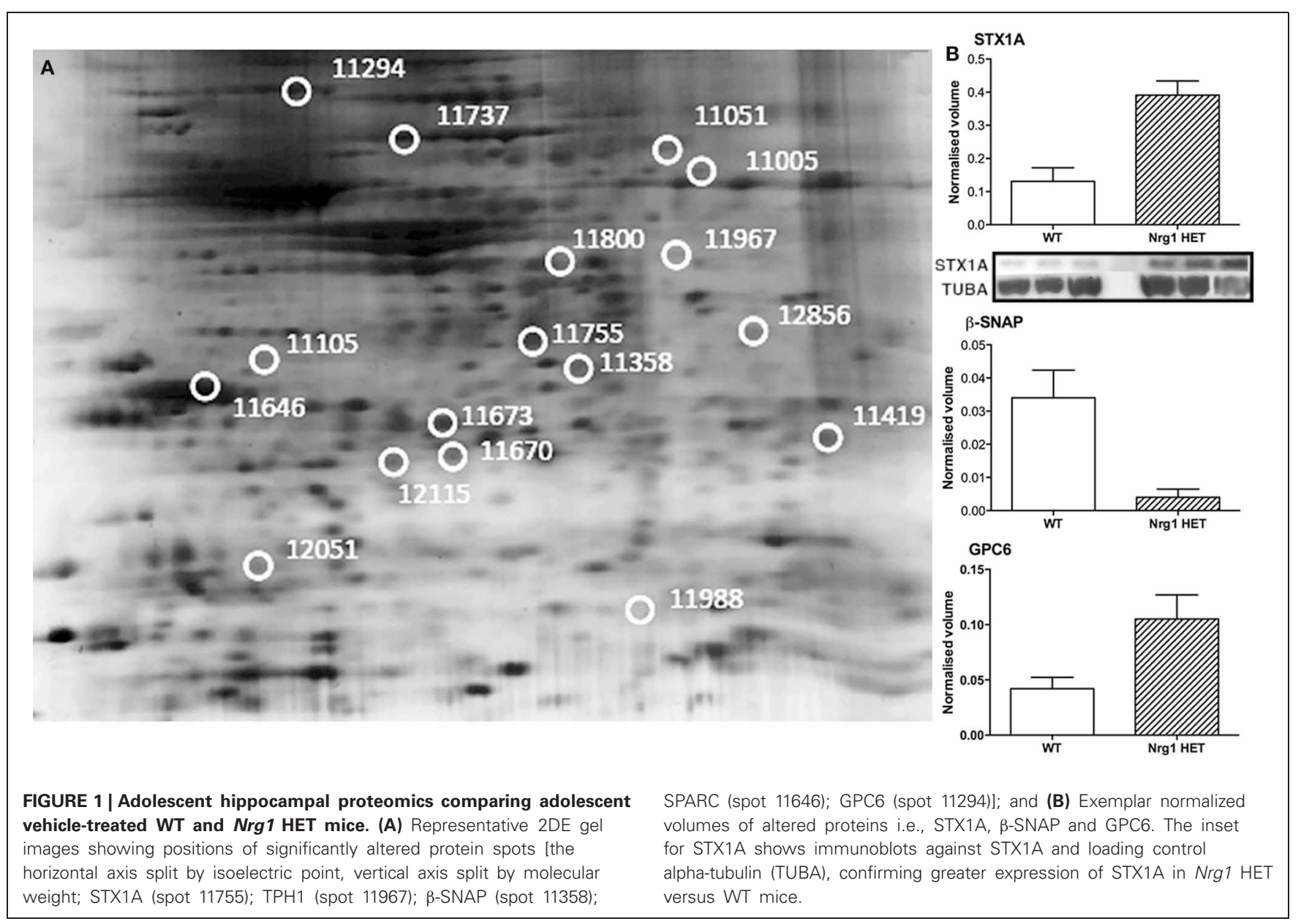

a platform for future work to confirm and more fully characterize the role of various novel proteins in the effects of $\mathrm{Nrgl}$ hypomorphism, THC and Nrg1-THC interactions.

\section{DISTINCT PROTEIN EXPRESSION IN THE HIPPOCAMPUS OF ADOLESCENT Nrg1 HET AND WT MICE}

Disordered neurotransmission is involved in the pathophysiology of schizophrenia and NRG1, a schizophrenia susceptibility gene, regulates neurotransmitter receptor expression and synaptic plasticity (Mei and Xiong, 2008). Here we provide evidence that heterozygous deletion of Nrg1 alters numerous proteins involved in the transport, fusion and recycling of synaptic vesicles, all processes critical to neurotransmitter release and synaptic function. The soluble N-ethylmaleimide-sensitive fusion attachment protein receptor (SNARE) complex regulates exocytotic release of neurotransmitters from presynaptic terminals and alterations in SNARE mRNA and protein is observed in post-mortem schizophrenia brain (Ramakrishnan et al., 2012). Here we show for the first time that Nrgl hypomorphism alters the expression of various SNARE proteins including STX1A, STX7, and $\beta$-SNAP.

STX1A was increased almost three-fold in Nrg1 HET mice relative to WT controls and this change was confirmed by Western blot analysis. Located within the pre-synaptic membrane, STX1A combines with $25 \mathrm{kDa}$ synaptosome-associated protein SNAP25 and vesicle-associated membrane protein 2 to form a complex that drives vesicle and presynaptic membrane fusion necessary for neurotransmitter exocytosis. Concordant with our findings in Nrg1 HET mice, STX1A is upregulated in the hippocampus and cingulate cortex of schizophrenic patients (Gabriel et al., 1997; Honer et al., 1997; Sokolov et al., 2000; Clark et al., 2007). We also demonstrate here that STX7, a member of an endocytic SNARE complex, was upregulated in Nrg1 HET mice compared to WT mice. STX7 mediates endocytic trafficking from early endosomes to late endosomes, and is necessary for fusion of late endosomes to lysosomes (Mullock et al., 2000; Nakamura et al., 2000). $\beta$-SNAP displayed an almost 9-fold reduction in expression in Nrg1 HET mice compared to WT mice. $\beta$-SNAP belongs to a class of proteins known as SNAPs, which form complexes with SNARE proteins to assist with membrane fusion before being dissociated by the ATPase $\mathrm{N}$-ethylmaleimide-sensitive factor. In contrast to other SNAPs, $\beta$-SNAP is localized to neural tissue, including hippocampal cells (Schiavo et al., 1995).

Nrg1 HET mice also displayed altered expression of several proteins involved in protein transport between the endoplasmic reticulum (ER) and Golgi apparatus. These included $\beta$ SNAP, dynactin subunit 2 (DCTN2) and ADP-ribosyl cyclase 2 (BST-1). Transport of protein from the ER to the Golgi is important to protein sorting and the dispatch of protein to cellular 


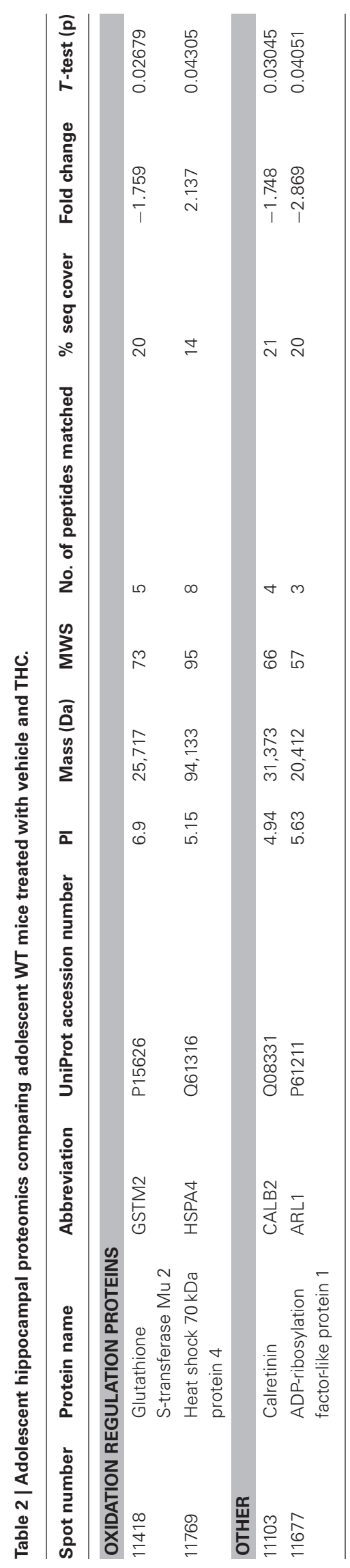

locations. An increased expression of DCTN2 was also observed in Nrg1 HET mice. DCTN2 is a functional subunit of dynactin, a component of the dynein-dynactin system. DCTN2 overexpression inhibits dynactin, and therefore dynein functions such as dynein-dependent maintenance of membrane organelle distribution (Burkhardt et al., 1997). DCTN2 is associated with syntaxin 18, an ER-localized SNARE involved in membrane trafficking between the ER and Golgi (Arasaki et al., 2006). BST-1, which was downregulated in Nrg1 HET mice, is also implicated in ER to Golgi transport as it suppressed such trafficking in yeast cells (Sompol et al., 2011).

Previous studies suggest that Nrg1 hypomorphism affects serotonergic neurotransmission, by altering the expression of $5-\mathrm{HT}_{2 \mathrm{~A}}$ receptors and the serotonin transporter in various brain regions of both adolescent and adult mice (Dean et al., 2008; Long et al., 2013). The observation that Nrg1 HET mice had reduced expression of TPH1 and increased level of AA-NAT is consistent with this notion. TPH1 is one of two isoforms of the enzyme involved in the rate-limiting synthesis of serotonin. Polymorphism in TPH1 is associated with increased risk for various psychiatric disorders including schizophrenia and bipolar disorder (Saetre et al., 2010; Seifuddin et al., 2012) and varies with neurodevelopment with peaks at PND 21 before decreasing in adulthood (Nakamura et al., 2006). Given the autocrine role of serotonin in guiding the development of serotonergic neurons (Gaspar et al., 2003), reduced TPH1 expression in adolescent Nrg1 HET mice may reflect aberrant development of serotonergic brain circuitry in these mice. AA-NAT, which converts serotonin to Nacetylserotonin, was also upregulated in the hippocampus of $\mathrm{Nrgl}$ HET mice. This role of this enzyme is well characterized in the pineal gland due to its involvement in melatonin synthesis and sleep-wake cycles (Zheng and Cole, 2002). However, the function of AA-NAT in other brain regions including the hippocampus is poorly understood. AA-NAT is expressed in a non-diurnal dependent manner in the hippocampus (Uz et al., 2002) and promotes hippocampal neuroprogenitor cell proliferation in mice (Sompol et al., 2011).

Given that Nrg1 is a neurotrophic factor it is not entirely surprising that Nrg1 HET mice display altered expression of the growth factor fibroblast growth factor 14 (FGF14) and regulators of growth factor protein expression, including SPARC and GPC6. FGF14 knockout mice, like Nrg1 HET mice, display locomotor hyperactivity, spatial learning deficits and impaired hippocampal long-term potentiation associated with lowered presynaptic vesicle docking (Wozniak et al., 2007; Xiao et al., 2007). The latter effect is relevant given the altered proteins involved in vesicle docking we observed here in Nrgl HET mice. The reduced level of FGF14 might be related to the increased expression of GPC6 and SPARC. Glypicans are heparan sulphate proteoglycans that act as co-receptors for growth factors and modulate fibroblast growth factor signaling (Paine-Saunders et al., 1999; Galli et al., 2003). GPC6 has recently been identified as a gene that confers susceptibility to formal thought disorder in schizophrenia and as a factor released from astrocytes that supports the formation of glutamatergic synapses via GluA1 AMPA receptors (Allen et al., 2012; Wang et al., 2012). Similar to GPC6, SPARC is released from astrocytes and modulates the formation 


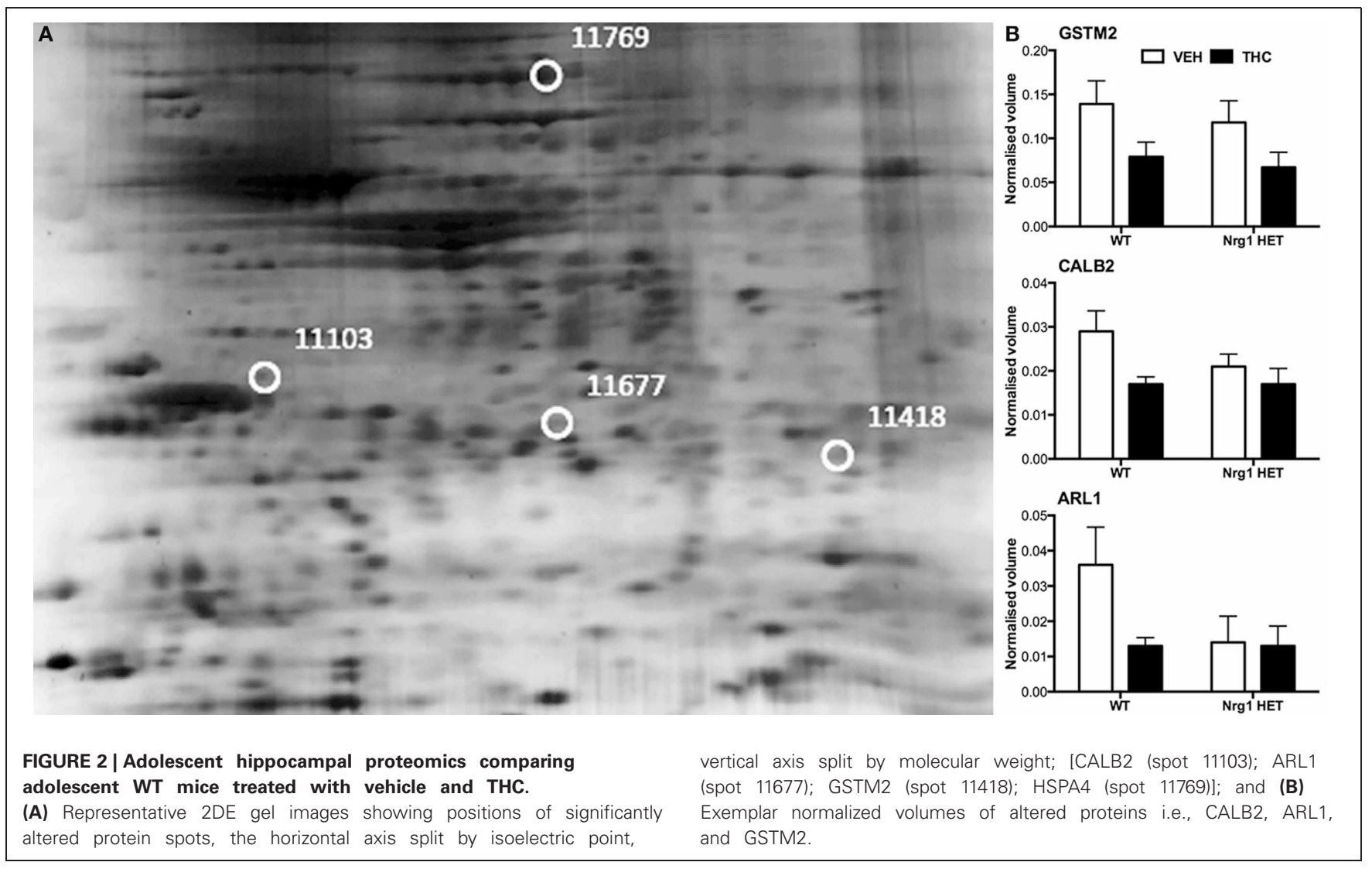

of excitatory synapses and FGF expression (Kucukdereli et al., 2011; Bradshaw, 2012). Taken together these findings suggest a novel link between Nrg1 and other interrelated growth factorrelated proteins FG14, GPC6, and SPARC, worthy of further examination in future studies.

The hippocampus of adolescent Nrg1 HET mice displayed altered expression of various proteins that influence cell survival and neuroinflammation including AVEN, ABIN2, and RGS10. Nrg1 exerts neuroprotective effects via inhibiting apoptosis triggered by various challenges (Chen et al., 2011; Li et al., 2012; Woo et al., 2012). AVEN inhibits apoptosis (Chau et al., 2000; Figueroa et al., 2004; Kutuk et al., 2010), therefore the reduction of AVEN in the hippocampus of Nrg1 HET mice might confer greater vulnerability to apoptosis in these mice. Adolescent Nrg1 HET mice displayed a trend toward increased expression of the pro-apoptotic and inflammatory cytokine TNF- $\alpha$ in the hippocampus and schizophrenia patients with a missense mutation in the transmembrane domain of NRG1 show heightened expression of TNF- $\alpha$ from B cells (Marballi et al., 2010; Desbonnet et al., 2012). This is interesting as ABIN-2 and RGS10, two proteins altered in Nrg1 HET mice, modulate the action of the TNF- $\alpha$. ABIN-2 prevents TNF- $\alpha$ mediated pro-apoptotic effects and its decreased expression in Nrg1 HET mice might reflect again a greater propensity to hippocampal apoptosis (Verstrepen et al., 2009). Perhaps as a compensatory mechanism Nrg1 HET mice showed increased expression of RGS10, a protein which renders cells resistant to TNF- $\alpha$ induced apoptosis (Lee et al., 2012).
Future studies are required to confirm whether altered apoptosis and neuroinflammation exists in Nrg1 HET mice.

\section{DIFFERENTIAL EFFECTS OF THC ON THE PROTEOME OF Nrg1 HET MICE vs. WT MICE}

Our prior research shows that Nrg1 heterozygotes display an altered neurobehavioral response to cannabinoids (Boucher et al., 2007a,b, 2011; Arnold et al., 2012; Long et al., 2013). Nrg1 mutant mice were more sensitive to the behavioral actions of acute THC compared to WT littermates in a sex-specific manner, with males being selectively affected but not females (Boucher et al., 2007a; Long et al., 2010). In a repeated dosing study, tolerance to cannabinoid-induced hypothermia and locomotor suppression developed more rapidly in Nrg1 HET than WT mice (Boucher et al., 2011). Conversely, only WT mice developed tolerance to cannabinoid-induced anxiety and Nrg1 HET mice maintained a persistent anxiogenic response to repeated cannabinoid exposure. Acute and repeated cannabinoid exposure selectively activated expression of Fos transcription factors in the lateral septum of Nrg1 HET mice but not WT mice (Boucher et al., 2007b, 2011). We also examined whether Nrg1 hypomorphism confers vulnerability to the neurobehavioral actions of acute or repeated THC exposure in adolescence (Long et al., 2013). THC exposure exacerbated the hyperlocomotor phenotype of Nrg1 HET mice expressed after withdrawal of the drug. Further, repeated THC administration also promoted differential effects on $\mathrm{CB}_{1}$ receptor, $5-\mathrm{HT}_{2 \mathrm{~A}}$ and NMDA receptor binding. Notably adolescent THC 

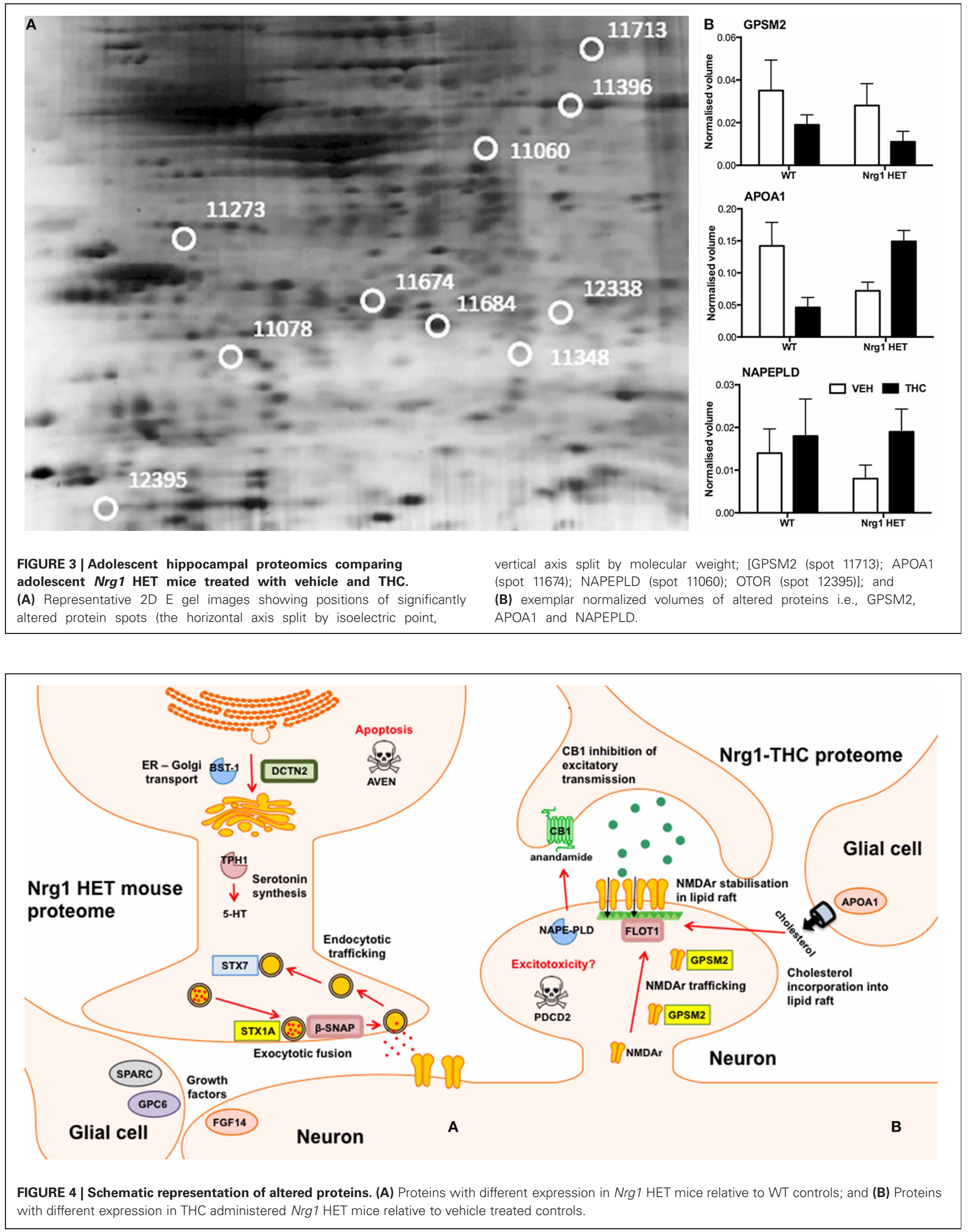
exposure selectively increased NMDA receptor expression in the hippocampus of Nrgl HET but not WT mice. Given these findings it is perhaps not surprising that the impact of repeated THC treatment as measured by proteomics was quite distinct in $\mathrm{Nrgl}$ HET mice vs. WT mice, with no overlap in differentially expressed proteins Table 3.

Nevertheless, our findings show some degree of overlap with previous examinations of THC effects on the rodent brain proteome (Quinn et al., 2008; Colombo et al., 2009; Rubino et al., 2009a; Filipeanu et al., 2011; Wang et al., 2011). THC treatment in adolescent rats modulated proteins regulating oxidative stress such as glutathione S-transferase and heat shock proteins (Quinn et al., 2008). Our results replicate the finding that repeated THC exposure decreased the expression of GSTM2 in the hippocampus (Quinn et al., 2008). GSTM2 catalysis the conjugation of reduced glutathione to electrophilic compounds thereby reducing the deleterious effects of reactive oxygen species (ROS) on cellular lipid, protein and DNA. By reducing levels of GSTM2, THC may render the hippocampus more vulnerable to oxidative stress and this may be linked to the long-term memory impairing effects of cannabinoids (Quinn et al., 2008; Boucher et al., 2009). Phencyclidine, another drug of abuse that promotes schizophrenia-relevant behaviors and cognitive dysfunction, also reduced glutathione levels and antioxidant defense enzymes in the rodent brain (Radonjic et al., 2010; Stojković et al., 2012). Interestingly, copy number variants in genes encoding glutathione S-transferase may be involved in susceptibility to schizophrenia (Rodriguez-Santiago et al., 2010). Here we also showed repeated adolescent THC exposure upregulated the expression of heat shock protein $70 \mathrm{kDa}$ in the hippocampus. Previous studies illustrated effects of rodent THC exposure on heat shock protein $70 \mathrm{kDa}$, heat shock cognate $71 \mathrm{kDa}$ protein and heat shock $60 \mathrm{kDa}$ protein (Bindukumar et al., 2008; Quinn et al., 2008; Colombo et al., 2009; Rubino et al., 2009a; Filipeanu et al., 2011). Heat shock proteins regulate cellular stress responses and provide protection against oxidative stress (Quinn et al., 2008; Stetler et al., 2010) so their increased expression may signify greater oxidative stress in the hippocampus. Heat shock protein $70 \mathrm{kDa}$ may also serve an autophagic function facilitating the clearance of toxic proteins and assisting in neuronal survival (Stetler et al., 2010).

Adolescent THC exposure decreased hippocampal levels of the calcium-binding protein CALB2. $\mathrm{CB}_{1}$ receptors are expressed on calretinin-positive GABA interneurons in the hippocampus (Marsicano and Lutz, 1999; Morozov et al., 2009). THC exposure in C57/BL6 mice increased expression of this protein in the cerebellum (Colombo et al., 2009). Colombo et al. (2009) analyzed CALB2 expression in the membrane whereas we assessed the cytosolic fraction, therefore it remains possible our finding may reflect translocation of the protein from the cytosol to the membrane. We isolated a novel protein, (ARL1), which was downregulated in response to THC exposure. Alcohol and methamphetamine administration similarly alter expression of this protein (Iwazaki et al., 2008; Kobeissy et al., 2008; Kashem et al., 2009). ARL1 is a Ras GTPase involved in retrograde trafficking of endosomes between the Golgi apparatus and the membrane in mammalian cells (Nishimoto-Morita et al., 2009).

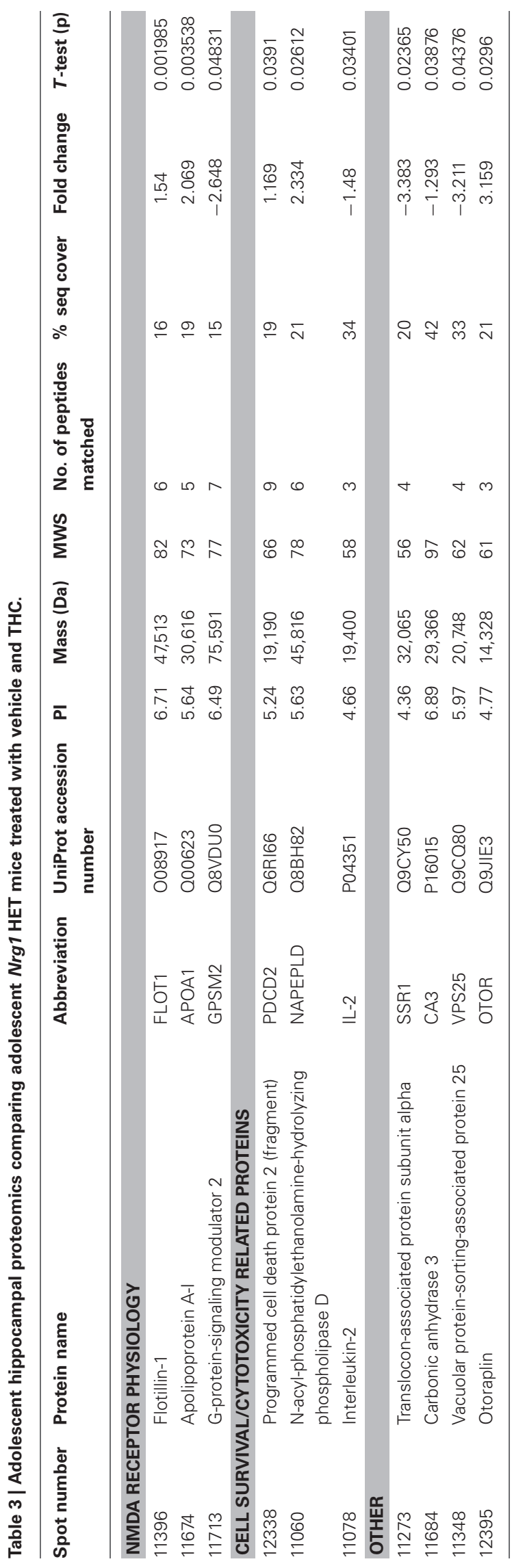


A THC-induced reduction in ARL1 may then disrupt the distribution of intracellular protein transport in the hippocampus.

Proteins selectively altered in Nrgl HET mice treated with THC include those that affect synapse formation and the dynamics of dendritic spines. Nrgl is a neurotrophic factor involved in spinogenesis through its modulation of NMDA receptor function (Li et al., 2007; Chen et al., 2008; Barros et al., 2009; Bennett, 2011; Nason et al., 2011). Adolescent THC exposure reduced the density of dendritic spines in the hippocampus via modulation of a number of proteins important to spine dynamics such as PSD-95 and NMDA receptors (Rubino et al., 2009b). Nrg1 hypomorphism might abnormally increase dendritic spine density in the hippocampus in response to THC as adolescent Nrg1 HET mice treated with THC displayed increased NMDA receptor binding in the hippocampus (Long et al., 2013). Our proteomic findings indicate altered expression in a number of proteins involved in intracellular trafficking and stabilization of NMDA receptors at the synapse. These include FLOT1, APOA1, and GPSM2.

GPSM2 traffics intracellular NMDA receptors to the synaptic membrane and facilitates spinogenesis by forming a macromolecular complex with NMDA receptors and synapse associated protein 102 (Sans et al., 2005). The reduced level of GPSM2 we observed in THC-treated Nrg1 HET mice may reflect GPSM2 being incorporated into the macromolecular complex, lowering the observed expression of free, unconjugated GPSM2. Further, Nrg1 HET mice treated with THC showed a selective increase in FLOT1 expression in the hippocampus, a protein that helps stabilize lipid rafts in the membrane. FLO T1 mediates neurite branching and dendritic spine dynamics in the hippocampus (Swanwick et al., 2010; Raemaekers et al., 2012). It also regulates the formation of glutamatergic synapses and interacts with NMDA receptors, possibly to enhance NMDA receptor clustering or trafficking to the membrane (Allen et al., 2007; Swanwick et al., 2009, 2010). Lipid rafts are constituted by cholesterol and sphingolipids (Mauch et al., 2001; Hering et al., 2003). APOA1, a protein that stimulates cholesterol release from glia, was upregulated in THC exposed Nrg1 HET mice (Hirsch-Reinshagen et al., 2004; Karten et al., 2005). Therefore, APOA1, by increasing the availability of cholesterol for incorporation into lipid rafts, may have in turn assisted in the molecular events required to stabilize NMDA

\section{REFERENCES}

Allen, J. A., Halverson-Tamboli,

R. A., and Rasenick, M. M.

(2007). Lipid raft microdomains and neurotransmitter signalling. Nat. Rev. Neurosci. 8, 128-140.

Allen, N. J., Bennett, M. L., Foo, L. C., Wang, G. X., Chakraborty, C., Smith, S. J., et al. (2012). Astrocyte glypicans 4 and 6 promote formation of excitatory synapses via GluA1 AMPA receptors. Nature 486, 410-414.

Arasaki, K., Taniguchi, M., Tani, K., and Tagaya, M. (2006). RINT-1 regulates the localization and entry of ZW10 to the syntaxin 18 complex. Mol. Biol. Cell 17, 2780-2788.

Arnold, J. C., Boucher, A. A., and Karl, T. (2012). The yin and yang of cannabis-induced psychosis: the actions of delta 9-tetrahydrocannabinol and cannabidiol in rodent models of Schizophrenia. Curr. Pharm. Des. 18, 5113-5130.

Ayalew, M., Le-Niculescu, H., Levey, D. F., Jain, N., Changala, B., Patel, S. D., et al. (2012). Convergent functional genomics of schizophrenia: from comprehensive understanding to genetic risk prediction. Mol. Psychiatry 17, 887-905.

receptors at the synaptic membrane. Interestingly, APOA1 is altered in schizophrenia brain (Huang et al., 2008).

The increased excitatory transmission mediated by increased NMDA receptors in THC-treated Nrg1 HET mice might also increase the expression of the apoptotic marker PCD2 and anandamide synthesizing enzyme NAPEPLD (Howlett et al., 2011), proteins reflecting heightened excitotoxicity/apoptosis and a homeostatic attempt to dampen increased NMDA receptor activation respectively. These results are consistent with $\mathrm{Nrg1-}$ cannabinoid interactions dysregulating the septohippocampal system. Increased excitation in the hippocampus of THC-treated Nrg1 HET mice might then influence downstream activity of the lateral septum, a region we have repeatedly shown to be selectively activated in Nrg1 HET mice in response to THC (Boucher et al., 2007b, 2011).

\section{CONCLUSIONS}

Using a proteomic approach we have uncovered numerous novel proteins that may be subject to regulation by disturbed $\mathrm{Nrg} 1$ signaling. Our findings also illuminate a potential constellation of molecular changes that may subserve the behavioral abnormalities that are observed in the Nrg1 transmembrane domain heterozygous mouse as well as their idiosyncratic response to repeated cannabinoid treatment. This may have implications for our overall understanding of genetic vulnerability to schizophrenia and to the exacerbation of psychosis sometimes caused by cannabis.

\section{ACKNOWLEDGMENTS}

This work was supported by a University of Sydney Bridging Grant to Jonathon C. Arnold. Jonathon C. Arnold is also supported by the Brain and Behavior Research Foundation (formerly National Alliance for Research on Schizophrenia and Depression: Young Investigator Awards). Tim Karl is supported by the Schizophrenia Research Institute utilizing infrastructure funding from NSW Ministry of Health, a project grant (1003886) and a career development award (568752) of the National Health and Medical Research Council, and a research grant from the Motor Neuron Disease Research Institute of Australia (Mick Rodger Benalla MND Research Grant). ISM is supported by the Australian Research Council.

Barros, C. S., Calabrese, B., Chamero, P., Roberts, A. J., Korzus, E., Lloyd, K., et al. (2009). Impaired maturation of dendritic spines without disorganization of cortical cell layers in mice lacking $N R G 1 /$ ErbB signaling in the central nervous system. Proc. Natl. Acad. Sci. U.S.A. 106, 4507-4512.

Bennett, M. R. (2011). Schizophrenia: susceptibility genes, dendritic-spine pathology and gray matter loss. Prog. Neurobiol. 95, 275-300.

Bindukumar, B., Mahajan, S. D. Reynolds, J. L., Hu, Z., Sykes, D. E., Aalinkeel, R., et al. (2008). Genomic and proteomic analysis of the effects of cannabinoids on normal human astrocytes. Brain Res. 1191, 1-11.

Bjarnadottir, M., Misner, D. L. Haverfield-Gross, S., Bruun, S., Helgason, V. G., Stefansson, H., et al. (2007). Neuregulin1 (NRG1) signaling through Fyn modulates NMDA receptor phosphorylation: differential synaptic function in NRG1 \pm knock-outs compared with wild-type mice. J. Neurosci. 27, 4519-4529.

Boucher, A. A., Arnold, J. C., Duffy, L., Schofield, P. R., Micheau, J., and Karl, T. (2007a). Heterozygous neuregulin 1 mice are more sensitive to the behavioural effects 
of Delta9-tetrahydrocannabinol. Psychopharmacology (Berl.) 192, 325-336.

Boucher, A. A., Hunt, G. E., Karl, T., Micheau, J., McGregor, I. S., and Arnold, J. C. (2007b). Heterozygous neuregulin 1 mice display greater baseline and Delta(9)-tetrahydrocannabinol-induced c-Fos expression. Neuroscience 149, 861-870.

Boucher, A. A., Hunt, G. E., Micheau, J., Huang, X., McGregor, I. S., Karl, T., et al. (2011). The schizophrenia susceptibility gene neuregulin 1 modulates tolerance to the effects of cannabinoids. Int. J. Neuropsychopharmacol. 14, 631-643.

Boucher, A. A., Vivier, L., MetnaLaurent, M., Brayda-Bruno, L., Mons, N., Arnold, J. C., et al. (2009). Chronic treatment with Delta(9)-tetrahydrocannabinol impairs spatial memory and reduces zif268 expression in the mouse forebrain. Behav. Pharmacol. 20, 45-55.

Bradshaw, A. D. (2012). Diverse biological functions of the SPARC family of proteins. Int. J. Biochem. Cell Biol. 44, 480-488.

Burkhardt, J. K., Echeverri, C. J., Nilsson, T., and Vallee, R. B. (1997). Overexpression of the dynamitin (p50) subunit of the dynactin complex disrupts dynein-dependent maintenance of membrane organelle distribution. J. Cell Biol. 139, 469-484.

Casey, B. J., Jones, R. M., and Hare, T. A. (2008). The adolescent brain. Ann. N.Y. Acad. Sci. 1124, 111-126.

Chau, B. N., Cheng, E. H., Kerr, D. A., and Hardwick, J. M. (2000). Aven, a novel inhibitor of caspase activation, binds Bcl-xL and Apaf-1. Mol. Cell 6, 31-40.

Chen, Y., Zhang, M., Li, Q., Guo, Y., Ding, W., Wang, L., et al. (2011). Interfering effect and mechanism of neuregulin on experimental dementia model in rats. Behav. Brain Res. $222,321-325$.

Chen, Y. J., Johnson, M. A., Lieberman, M. D., Goodchild, R. E., Schobel, S., Lewandowski, N., et al. (2008). Type III neuregulin-1 is required for normal sensorimotor gating, memoryrelated behaviors, and corticostriatal circuit components. J. Neurosci. $28,6872-6883$.

Chesworth, R., Yulyaningsih, E., Cappas, E., Arnold, J., Sainsbury, A., and Karl, T. (2012). The response of neuregulin 1 mutant mice to acute restraint stress. Neurosci. Lett. 515, 82-86.
Chong, V. Z., Thompson, M., Beltaifa, S., Webster, M. J., Law, A. J., and Weickert, C. S. (2008). Elevated neuregulin-1 and ErbB4 protein in the prefrontal cortex of schizophrenic patients. Schizophr. Res. 100, 270-280.

Clark, D., Dedova, I., Cordwell, S. and Matsumoto, I. (2007). Altered proteins of the anterior cingulate cortex white matter proteome in schizophrenia. Proteomics Clin. Appl. 1, 157-166.

Colombo, G., Rusconi, F., Rubino, T., Cattaneo, A., Martegani, E., Parolaro, D., et al. (2009). Transcriptomic and proteomic analyses of mouse cerebellum reveals alterations in RasGRF1 expression following in vivo chronic treatment with delta 9-tetrahydrocannabinol. J. Mol. Neurosci. 37, 111-122.

Dean, B., Karl, T., Pavey, G., Boer, S., Duffy, L., and Scarr, E. (2008). Increased levels of serotonin $2 \mathrm{~A}$ receptors and serotonin transporter in the CNS of neuregulin 1 hypomorphic/mutant mice. Schizophr. Res. 99, 341-349.

Desbonnet, L., O’Tuathaigh, C., Clarke, G., O’Leary, C., Petit, E., Clarke, N. et al. (2012). Phenotypic effects of repeated psychosocial stress during adolescence in mice mutant for the schizophrenia risk gene neuregulin1: a putative model of gene $\mathrm{x}$ environment interaction. Brain Behav. Immun. 26, 660-671.

Duffy, L., Cappas, E., Lai, D., Boucher, A. A., and Karl, T. (2010). Cognition in transmembrane domain neuregulin 1 mutant mice. Neuroscience $170,800-807$.

Figueroa, B. Jr., Chen, S., Oyler, G. A., Hardwick, J. M., and Betenbaugh, M. J. (2004). Aven and Bcl-xL enhance protection against apoptosis for mammalian cells exposed to various culture conditions. Biotechnol. Bioeng. 85, 589-600.

Filipeanu, C. M., Guidry, J. J., Leonard, S. T., and Winsauer, P. J. (2011). Delta9-THC increases endogenous AHA1 expression in rat cerebellum and may modulate CB1 receptor function during chronic use. J. Neurochem. 118, 1101-1112.

Gabriel, S. M., Haroutunian, V., Powchik, P., Honer, W. G., Davidson, M., Davies, P., et al. (1997). Increased concentrations of presynaptic proteins in the cingulate cortex of subjects with schizophrenia. Arch. Gen. Psychiatry 54, 559-566.

Galli, A., Roure, A., Zeller, R., and Dono, R. (2003). Glypican 4 modulates FGF signalling and regulates dorsoventral forebrain patterning in Xenopus embryos. Development 130, 4919-4929.

Gaspar, P., Cases, O., and Maroteaux, L. (2003). The developmental role of serotonin: news from mouse molecular genetics. Nat. Rev. Neurosci. 4 1002-1012.

Giedd, J. N., Blumenthal, J., Jeffries, N. O., Castellanos, F. X., Liu, H., Zijdenbos, A., et al. (1999). Brain development during childhood and adolescence: a longitudinal MRI study. Nat. Neurosci. 2, 861-863.

Greenwood, T. A., Light, G. A. Swerdlow, N. R., Radant, A. D. and Braff, D. L. (2012). Association analysis of 94 candidate genes and schizophrenia-related endophenotypes. PLoS ONE 7:e29630. doi 10.1371/journal.pone.0029630

Han, S., Yang, B. Z., Kranzler, H. R. Oslin, D., Anton, R., Farrer, L. A., et al. (2012). Linkage analysis followed by association show NRG1 associated with cannabis dependence in African Americans. Mol. Psychiatry 72, 637-644.

Hashimoto, R., Straub, R. E., Weickert, C. S., Hyde, T. M., Kleinman, J. E., and Weinberger, D. R. (2004). Expression analysis of neuregulin- 1 in the dorsolateral prefrontal cortex in schizophrenia. Mol. Psychiatry 9 , 299-307.

Hering, H., Lin, C. C., and Sheng, M. (2003). Lipid rafts in the maintenance of synapses, dendritic spines, and surface AMPA receptor stability. J. Neurosci. 23, 3262-3271.

Herkenham, M., Lynn, A. B., Little, M. D., Johnson, M. R., Melvin, L. S., de Costa, B. R., et al. (1990). Cannabinoid receptor localization in brain. Proc. Natl. Acad. Sci. U.S.A. 87, 1932-1936.

Hirsch-Reinshagen, V., Zhou, S. Burgess, B. L., Bernier, L., McIsaac, S. A., Chan, J. Y., et al. (2004). Deficiency of ABCA1 impairs apolipoprotein E metabolism in brain. J. Biol. Chem. 279, 41197-41207.

Honer, W. G., Falkai, P., Young, C., Wang, T., Xie, J., Bonner, J., et al. (1997). Cingulate cortex synaptic terminal proteins and neural cell adhesion molecule in schizophrenia. Neuroscience 78, 99-110.

Hong, L. E., Wonodi, I., Stine, O. C., Mitchell, B. D., and Thaker, G. K. (2008). Evidence of missense mutations on the neuregulin 1 gene affecting function of prepulse inhibition. Biol. Psychiatry 63, 17-23.

Howlett, A. C., Reggio, P. H., Childers, S. R., Hampson, R. E., Ulloa, N. M., and Deutsch, D. G. (2011). Endocannabinoid tone versus constitutive activity of cannabinoid receptors. Br. J. Pharmacol. 163, 1329-1343.

Huang, J. T., Wang, L., Prabakaran, S., Wengenroth, M., Lockstone, H. E., Koethe, D., et al. (2008). Independent protein-profiling studies show a decrease in apolipoprotein A1 levels in schizophrenia CSF, brain and peripheral tissues. Mol. Psychiatry 13, 1118-1128.

Iwazaki, T., McGregor, I. S., and Matsumoto, I. (2008). Protein expression profile in the amygdala of rats with methamphetamineinduced behavioral sensitization. Neurosci. Lett. 435, 113-119.

Karl, T., Duffy, L., Scimone, A., Harvey, R. P., and Schofield, P. R. (2007). Altered motor activity, exploration and anxiety in heterozygous neuregulin 1 mutant mice: implications for understanding schizophrenia. Genes Brain Behav. 6 , 677-687.

Karten, B., Hayashi, H., Francis, G. A., Campenot, R. B., Vance, D. E., and Vance, J. E. (2005). Generation and function of astroglial lipoproteins from Niemann-Pick type C1deficient mice. Biochem. J. 387, 779-788.

Kashem, M. A., Sarker, R., Des Etages, H., Machaalani, R., King, N., McGregor, I. S., et al. (2009) Comparative proteomics in the corpus callosal sub-regions of postmortem human brain. Neurochem. Int. 55, 483-490.

Kobeissy, F. H., Warren, M. W., Ottens, A. K., Sadasivan, S., Zhang, Z., Gold, M. S., et al. (2008). Psychoproteomic analysis of rat cortex following acute methamphetamine exposure. J. Proteome Res. 7, 1971-1983.

Kucukdereli, H., Allen, N. J., Lee, A. T., Feng, A., Ozlu, M. I., Conatser, L. M., et al. (2011). Control of excitatory CNS synaptogenesis by astrocyte-secreted proteins Hevin and SPARC. Proc. Natl. Acad. Sci. U.S.A. 108, E440-E449.

Kutuk, O., Temel, S. G., Tolunay, S., and Basaga, H. (2010). Aven blocks DNA damage-induced apoptosis by stabilising Bcl-xL. Eur. J. Cancer 46, 2494-2505.

Lee, J. K., Chung, J., Druey, K. M., and Tansey, M. G. (2012). RGS10 exerts a neuroprotective role through the PKA/c-AMP response-element (CREB) pathway in dopaminergic neuron-like cells. J. Neurochem. 122 , 333-343.

Li, B., Woo, R. S., Mei, L., and Malinow, R. (2007). The neuregulin-1 receptor erbB4 controls glutamatergic 
synapse maturation and plasticity. Neuron 54, 583-597.

Li, Y., Lein, P. J., Liu, C., Bruun, D. A., Giulivi, C., Ford, G. D., et al. (2012). Neuregulin-1 is neuroprotective in a rat model of organophosphateinduced delayed neuronal injury. Toxicol. Appl. Pharmacol. 262, 194-204.

Long, L. E., Chesworth, R., Arnold, J. C., and Karl, T. (2010). A follow-up study: acute behavioural effects of Delta(9)-THC in female heterozygous neuregulin 1 transmembrane domain mutant mice. Psychopharmacology (Berl.) 211, 277-289.

Long, L. E., Chesworth, R., Huang, X. F., McGregor, I. S., Arnold, J. C., and Karl, T. (2013). Transmembrane domain Nrg1 mutant mice show altered susceptibility to the neurobehavioural actions of repeated THC exposure in adolescence. Int. J. Neuropsychopharmacol. 16, 163-175.

Marballi, K., Cruz, D., Thompson, P., and Walss-Bass, C. (2012). Differential neuregulin 1 cleavage in the prefrontal cortex and hippocampus in schizophrenia and bipolar disorder: preliminary findings. PLoS ONE 7:e36431. doi: 10.1371/journal.pone.0036431

Marballi, K., Quinones, M. P., Jimenez, F., Escamilla, M. A., Raventos, H., Soto-Bernardini, M. C., et al. (2010). In vivo and in vitro genetic evidence of involvement of neuregulin 1 in immune system dysregulation. J. Mol. Med. (Berl.) 88, 1133-1141.

Marsicano, G., and Lutz, B. (1999). Expression of the cannabinoid receptor $\mathrm{CB} 1$ in distinct neuronal subpopulations in the adult mouse forebrain. Eur. J. Neurosci. 11, 4213-4225.

Mauch, D. H., Nagler, K., Schumacher, S., Goritz, C., Muller, E. C., Otto, A., et al. (2001). CNS synaptogenesis promoted by glia-derived cholesterol. Science 294, 1354-1357.

Mei, L., and Xiong, W. C. (2008). Neuregulin 1 in neural development, synaptic plasticity and schizophrenia. Nat. Rev. Neurosci. 9, 437-452.

Morozov, Y. M., Torii, M., and Rakic, P. (2009). Origin, early commitment, migratory routes, and destination of cannabinoid type 1 receptorcontaining interneurons. Cereb. Cortex 19(Suppl. 1), i78-i89.

Mullock, B. M., Smith, C. W., Ihrke, G., Bright, N. A., Lindsay, M., Parkinson, E. J., et al. (2000). Syntaxin 7 is localized to late endosome compartments, associates with Vamp 8, and Is required for late endosome-lysosome fusion. Mol. Biol. Cell 11, 3137-3153.

Nakamura, K., Sugawara, Y., Sawabe, K., Ohashi, A., Tsurui, H., Xiu, Y., et al. (2006). Late developmental stage-specific role of tryptophan hydroxylase 1 in brain serotonin levels. J. Neurosci. 26, 530-534.

Nakamura, N., Yamamoto, A., Wada, Y., and Futai, M. (2000). Syntaxin 7 mediates endocytic trafficking to late endosomes. J. Biol. Chem. 275, 6523-6529.

Nason, M. W. Jr., Adhikari, A., Bozinoski, M., Gordon, J. A., and Role, L. W. (2011). Disrupted activity in the hippocampalaccumbens circuit of type III neuregulin 1 mutant mice. Neuropsychopharmacology 36 , 488-496.

Nishimoto-Morita, K., Shin, H. W., Mitsuhashi, H., Kitamura, M., Zhang, Q., Johannes, L., et al. (2009). Differential effects of depletion of ARL1 and ARFRP1 on membrane trafficking between the trans-Golgi network and endosomes. J. Biol. Chem. 284, 10583-10592.

O’Tuathaigh, C. M., Babovic, D., O'Sullivan, G. J., Clifford, J. J., Tighe, O., Croke, D. T., et al. (2007). Phenotypic characterization of spatial cognition and social behavior in mice with 'knockout' of the schizophrenia risk gene neuregulin 1. Neuroscience 147 , $18-27$.

O'Tuathaigh, C. M., O'Connor, A. M., O'Sullivan, G. J., Lai, D., Harvey, R., Croke, D. T., et al. (2008). Disruption to social dyadic interactions but not emotional/anxiety-related behaviour in mice with heterozygous 'knockout' of the schizophrenia risk gene neuregulin1. Prog. Neuropsychopharmacol. Biol. Psychiatry 32, 462-466.

Paine-Saunders, S., Viviano, B. L., and Saunders, S. (1999). GPC6, a novel member of the glypican gene family, encodes a product structurally related to GPC4 and is colocalized with GPC5 on human chromosome 13. Genomics 57, 455-458.

Quinn, H. R., Matsumoto, I., Callaghan, P. D., Long, L. E. Arnold, J. C., Gunasekaran, N., et al. (2008). Adolescent rats find repeated Delta(9)-THC less aversive than adult rats but display greater residual cognitive deficits and changes in hippocampal protein expression following exposure. Neuropsychopharmacology 33, 1113-1126.
Radonjic, N. V., Knezevic, I. D., Vilimanovich, U., Kravic-Stevovic, T., Marina, L. V., Nikolic, T., et al. (2010). Decreased glutathione levels and altered antioxidant defense in an animal model of schizophrenia: long-term effects of perinatal phencyclidine administration. Neuropharmacology 58, 739-745.

Raemaekers, T., Peric, A., Baatsen, P., Sannerud, R., Declerck, I., Baert, V., et al. (2012). ARF6-mediated endosomal transport of Telencephalin affects dendritic filopodia-tospine maturation. $E M B O$ J. 31, 3252-3269.

Ramakrishnan, N. A., Drescher, M. J., and Drescher, D. G. (2012). The SNARE complex in neuronal and sensory cells. Mol. Cell. Neurosci. 50, 58-69.

Rodriguez-Santiago, B., Brunet, A., Sobrino, B., Serra-Juhe, C. Flores, R., Armengol, L., et al. (2010). Association of common copy number variants at the glutathione S-transferase genes and rare novel genomic changes with schizophrenia. Mol. Psychiatry 15, 1023-1033.

Roussos, P., Giakoumaki, S. G. Adamaki, E., and Bitsios, P. (2011). The influence of schizophrenia-related neuregulin-1 polymorphisms on sensorimotor gating in healthy males. Biol. Psychiatry 69, 479-486.

Rubino, T., Realini, N., Braida, D. Alberio, T., Capurro, V., Vigano, D., et al. (2009a). The depressive phenotype induced in adult female rats by adolescent exposure to THC is associated with cognitive impairment and altered neuroplasticity in the prefrontal cortex. Neurotox. Res. 15, 291-302.

Rubino, T., Realini, N., Braida, D. Guidi, S., Capurro, V., Vigano, D. et al. (2009b). Changes in hippocampal morphology and neuroplasticity induced by adolescent THC treatment are associated with cognitive impairment in adulthood. Hippocampus 19, 763-772.

Saetre, P., Lundmark, P., Wang, A., Hansen, T., Rasmussen, H. B., Djurovic, S., et al. (2010). The tryptophan hydroxylase 1 (TPH1) gene, schizophrenia susceptibility, and suicidal behavior: a multicentre case-control study and meta-analysis. Am. J. Med. Genet. B Neuropsychiatr. Genet. 153B 387-396.

Sans, N., Wang, P. Y., Du, Q., Petralia, R. S., Wang, Y. X., Nakka, S., et al. (2005). mPins modulates PSD-95 and SAP102 trafficking and influences NMDA receptor surface expression. Nat. Cell Biol. 7, $1179-1190$

Schiavo, G., Gmachl, M. J., Stenbeck, G., Sollner, T. H., and Rothman, J. E. (1995). A possible docking and fusion particle for synaptic transmission. Nature 378, 733-736.

Seifuddin, F., Mahon, P. B., Judy, J., Pirooznia, M., Jancic, D., Taylor, J., et al. (2012). Meta-analysis of genetic association studies on bipolar disorder. Am. J. Med. Genet. B Neuropsychiatr. Genet. 159B, 508-518.

Sokolov, B. P., Tcherepanov, A. A. Haroutunian, V., and Davis, K. L. (2000). Levels of mRNAs encoding synaptic vesicle and synaptic plasma membrane proteins in the temporal cortex of elderly schizophrenic patients. Biol. Psychiatry 48 184-196.

Sompol, P., Liu, X., Baba, K., Paul, K. N., Tosini, G., Iuvone, P. M., et al. (2011). N-acetylserotonin promotes hippocampal neuroprogenitor cell proliferation in sleep-deprived mice. Proc. Natl. Acad. Sci. U.S.A. 108, 8844-8849.

Spear, L. P. (2000). The adolescent brain and age-related behavioral manifestations. Neurosci. Biobehav. Rev. 24, 417-463.

Spencer, J. R., Darbyshire, K. M., Boucher, A. A., and Arnold, J. C. (2012). Adolescent neuregulin 1 heterozygous mice display enhanced behavioural sensitivity to methamphetamine. Prog. Neuropsychopharmacol. Biol. Psychiatry 39, 376-381.

Stefansson, H., Sigurdsson, E. Steinthorsdottir, V., Bjornsdottir, S., Sigmundsson, T., Ghosh, S., et al. (2002). Neuregulin 1 and susceptibility to schizophrenia. Am. J. Hum. Genet. 71, 877-892.

Stetler, R. A., Gan, Y., Zhang, W., Liou, A. K., Gao, Y., Cao, G., et al. (2010). Heat shock proteins: cellular and molecular mechanisms in the central nervous system. Prog. Neurobiol. 92, 184-211.

Stojković, T., Radonjić, N. V., Velimirović, M., Jevtić, G., Popović, V., Doknić, M., et al. (2012). Risperidone reverses phencyclidine induced decrease in glutathione levels and alterations of antioxidant defense in rat brain. Prog. Neuropsychopharmacol. Biol. Psychiatry 39, 192-199.

Swanwick, C. C., Shapiro, M. E., Vicini, S., and Wenthold, R. J. (2010). Flotillin-1 mediates neurite branching induced by synaptic adhesion-like molecule 4 in hippocampal neurons. Mol. Cell. Neurosci. 45, 213-225. 
Swanwick, C. C., Shapiro, M. E., Yi, Z., Chang, K., and Wenthold, R. J. (2009). NMDA receptors interact with flotillin-1 and -2, lipid raft-associated proteins. FEBS Lett. 583, 1226-1230.

Tsou, K., Brown, S., Sanudo-Pena, M. C., Mackie, K., and Walker, J. M. (1998). Immunohistochemical distribution of cannabinoid CB1 receptors in the rat central nervous system. Neuroscience 83, 393-411.

Uz, T., Qu, T., Sugaya, K., and Manev, H. (2002). Neuronal expression of arylalkylamine Nacetyltransferase (AANAT) mRNA in the rat brain. Neurosci. Res. 42, 309-316.

Verstrepen, L., Carpentier, I., Verhelst, K., and Beyaert, R. (2009). ABINs: A20 binding inhibitors of NF-kappa $\mathrm{B}$ and apoptosis signaling. Biochem. Pharmacol. 78, 105-114.

Vullhorst, D., Neddens, J., Karavanova, I., Tricoire, L., Petralia, R. S., McBain, C. J., et al. (2009). Selective expression of ErbB4 in interneurons, but not pyramidal cells, of the rodent hippocampus. J. Neurosci. 29, 12255-12264.

Wang, J., Yuan, W., and Li, M. D. (2011). Genes and pathways co-associated with the exposure to multiple drugs of abuse, including alcohol, amphetamine/methamphetamine, cocaine, marijuana, morphine, and/or nicotine: a review of proteomics analyses. Mol. Neurobiol. 44, 269-286.

Wang, K. S., Zhang, Q., Liu, X., Wu, L., and Zeng, M. (2012). PKNOX2 is associated with formal thought disorder in schizophrenia: a metaanalysis of two genome-wide association studies. J. Mol. Neurosci. 48, 265-272.

Weickert, C. S., Tiwari, Y., Schofield, P. R., Mowry, B. J., and Fullerton, J. M. (2012). Schizophrenia-associated HapICE haplotype is associated with increased NRG1 type III expression and high nucleotide diversity. Transl. Psychiatry 2:e104 doi: $10.1038 /$ tp.2012.25
Woo, R. S., Lee, J. H., Kim, H. S., Baek, C. H., Song, D. Y., Suh, Y. H., et al. (2012). Neuregulin-1 protects against neurotoxicities induced by Swedish amyloid precursor protein via the ErbB4 receptor. Neuroscience 202, 413-423.

Wozniak, D. F., Xiao, M., Xu, L. Yamada, K. A., and Ornitz, D. M. (2007). Impaired spatial learning and defective theta burst induced LTP in mice lacking fibroblast growth factor 14. Neurobiol. Dis. 26, 14-26.

Xiao, M., Xu, L., Laezza, F., Yamada, K., Feng, S., and Ornitz, D. M (2007). Impaired hippocampal synaptic transmission and plasticity in mice lacking fibroblast growth factor 14. Mol. Cell. Neurosci. 34, 366-377.

Zheng, W., and Cole, P. A. (2002). Serotonin N-acetyltransferase: mechanism and inhibition. Curr. Med. Chem. 9, 1187-1199.

Conflict of Interest Statement: The authors declare that the research was conducted in the absence of any commercial or financial relationships that could be construed as a potential conflict of interest.

Received: 30 November 2012; accepted: 06 February 2013; published online: 26 February 2013

Citation: Spencer JR, Darbyshire KME, Boucher AA, Kashem MA, Long LE, McGregor IS, Karl T and Arnold JC (2013) Novel molecular changes induced by Nrg1 hypomorphism and Nrg1cannabinoid interaction in adolescence: a hippocampal proteomic study in mice. Front. Cell. Neurosci. 7:15. doi: 10.3389/ fncel.2013.00015

Copyright (c) 2013 Spencer, Darbyshire, Boucher, Kashem, Long, McGregor, Karl and Arnold. This is an open-access article distributed under the terms of the Creative Commons Attribution License, which permits use, distribution and reproduction in other forums, provided the original authors and source are credited and subject to any copyright notices concerning any third-party graphics etc. 